\title{
Pocket Creation and Ring-thread Traction Facilitates Colorectal Endoscopic Submucosal Dissection for Non-experts
}

\author{
AYAKO FUJIMORI ${ }^{1}$, NORIKO NISHIYAMA ${ }^{1}$, HIDEKI KOBARA ${ }^{1}$, KAZUHIRO KODUKA $^{1}$, NAOYA TADA ${ }^{1}$, \\ TAKANORI MATSUI ${ }^{1}$, TAIGA CHIYO $^{1}$, NOBUYA KOBAYASHI ${ }^{1}$, SHINTARO FUJIHARA $^{1}$, TATSUO YACHIDA $^{1}$, \\ KEIICHI OKANO ${ }^{2}$, YASUYUKI SUZUKI ${ }^{2}$, DAISUKE NAKANO ${ }^{3}$, AKIRA NISHIYAMA ${ }^{3}$ and TSUTOMU MASAKI ${ }^{1}$ \\ ${ }^{1}$ Department of Gastroenterology and Neurology, \\ ${ }^{2}$ Department of Gastroenterological Surgery, and \\ ${ }^{3}$ Department of Pharmacology, Faculty of Medicine, Kagawa University, Kagawa, Japan
}

\begin{abstract}
Background/Aim: Colorectal endoscopic submucosal dissection (ESD) is a difficult technique. Counter-traction may facilitate the procedure but its efficacy in non-experts remains unclear. We determined the safety and efficacy of pocket creation and ring-thread traction (PRM) for non-expert colorectal ESD. Patients and Methods: We retrospectively compared patients who underwent conventional colorectal ESD (C-group, $n=50$ ) or PRM (pocket creation, whole-circumferential cutting, ring-thread traction, submucosal dissection; PRM-group, $n=48$ ). All procedures were performed by four non-experts, each with $\leq 40$ experiences of colorectal ESD. Results: Procedural time was significantly shorter in the PRM-group compared with the $C$-group $(p=0.007)$, with less additional device usage $(p<0.001)$. There also tended to be fewer perforation incidents and muscle injuries in the PRM-group. There were no significant differences in en bloc or $R 0$ resection rates between the groups. Conclusion: PRM may be a safe, useful, and cost-effective technique for non-experts learning to perform colorectal ESD.
\end{abstract}

Endoscopic submucosal dissection (ESD) is an established efficient method for achieving en bloc and curative R0 resection for early gastrointestinal cancerous lesions, regardless of lesion size, overcoming the limitation of

This article is freely accessible online.

Correspondence to: Hideki Kobara, MD, Department of Gastroenterology and Neurology, Faculty of Medicine, Kagawa University, 1750-1 Ikenobe, Miki, Kita, Kagawa 761-0793, Japan. Tel: +81 878912156, Fax: +81 878912158, e-mail: kobara@med.kagawau.ac.jp

Key Words: Endoscopic submucosal dissection, early colorectal cancer, trainee, counter traction. piecemeal endoscopic mucosal resection (1). ESD has been accepted as the standard treatment since favourable reports on short- and long-term outcomes in Japan and other Asian countries $(2,3)$. However, colorectal ESD remains challenging compared with oesophageal and gastric ESD (4). Thinner colon walls, especially in the proximal colon, the presence of flexures and folds, and peristaltic movements can all increase the technical difficulty. Colorectal ESD has thus been poorly adopted in Western countries, and the European Society of Gastrointestinal Endoscopy (ESGE) guidelines state that ESD should only be performed by experts (5). The key to success is maintaining an adequate visual field of the submucosal layer and drawing the cutting line for precise dissection during the procedure (6). One technical complication relates to the lack of counter-traction, and several traction methods have been developed to facilitate ESD, including S-O clip (7), tractionassist using clip and line $(8,9)$, ring-thread traction $(10)$, and multiloop traction (11).

Prior to traction, anchoring a hemoclip on the resected mucosal edge also remains an issue. Deployment of the hemoclip may result in fixation of the submucosal or muscle layer, thus interfering with the subsequent submucosal dissection. It is therefore necessary to create a mucosal flap ("submucosal pocket") to resolve this issue. The pocketcreation method introduced by Hayashi et al. has several advantages, including preventing injection leakage and maintaining a stable scope manoeuvre inside the pocket (12, 13). In this procedure, a submucosal pocket is created, allowing the endoscope to enter the submucosal space. There is currently no established strategy for performing safe and effective colorectal ESD, including making the initial approach and resecting the submucosa, suitable for use by non-experts. We therefore developed a novel strategy involving pocket creation and ring-thread traction (PRM) for achieving colorectal ESD. This study aimed to evaluate the safety and efficacy of PRM carried out by non-experts performing colorectal ESD. 


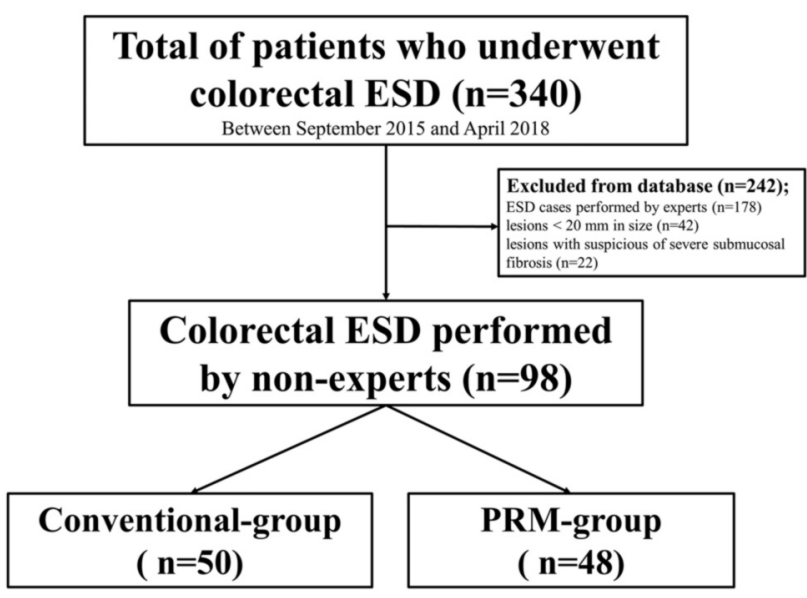

Figure 1. Flow chart showing recruitment of patients in this study.

\section{Patients and Methods}

Study population. All 340 patients who underwent colorectal ESD for adenoma or carcinoma, based on the Japanese guidelines for ESD and endoscopic mucosal resection (3) between September 2015 and April 2018, were reviewed. Data for 98 patients who received colorectal ESD performed by non-experts were extracted. Antithrombotic agents were stopped prior to ESD according to the current guidelines (14). Non-experts were defined as performers with $<40$ experiences of colorectal ESD. We performed "conventional ESD" between September 2015 and March 2016, but introduced a new "PRM-ESD" to improve the technical aspects between April 2016 and April 2018. The inclusion criteria were patients with colorectal neoplasms $\geq 20 \mathrm{~mm}$ in size, and procedure performed by non-experts. The exclusion criteria were superficial colorectal tumours $<20 \mathrm{~mm}$ maximum diameter, lesions with suspected severe submucosal fibrosis, and procedures performed by experts.

Study design. This was a single-centre, retrospective, comparative study conducted at Kagawa University Hospital. The 98 eligible patients were divided into a conventional ESD group (C-group, $\mathrm{n}=50$ ) and a PRM group (PRM-group, $\mathrm{n}=48$ ), and the groups were retrospectively compared. This study involved procedures carried out by four non-experts, who were supervised by expert endoscopists capable of taking over the procedure in difficult cases of colorectal ESD. The study flowchart for the two groups is shown in Figure 1. The study was approved by the Clinical Ethics Committee of Kagawa University Hospital (Registration No.: Hesei 30-024) in accordance with the Helsinki Declaration. All patients provided written informed consent to undergo the procedures and participate in the study.

Outcome measures. The primary outcome was total procedure time, defined as the interval from pre-cutting to the completion of specimen resection. Secondary outcomes were en bloc resection rate, curative resection rate, resection size, perforation and muscle injury rate during ESD, and additional device usage. En bloc resection was defined as the macroscopic removal of the whole tumour specimen in one piece. Curative resection (R0) was defined
Table I. Baseline characteristics.

\begin{tabular}{|c|c|c|c|}
\hline Parameters & $\begin{array}{l}\text { PRM group } \\
\quad(\mathrm{n}=48)\end{array}$ & $\begin{array}{l}\text { Conventional } \\
\text { group }(n=50)\end{array}$ & $p$-Value \\
\hline Age, median (range) & $72(51-85)$ & $70(45-87)$ & $0.06^{\mathrm{a}}$ \\
\hline Gender, male $(\%)$ & $31(65)$ & $38(76)$ & $0.27^{b}$ \\
\hline Tumor location, $\mathrm{n}(\%)$ & & & $0.19^{\mathrm{b}}$ \\
\hline Cecum & $13(27)$ & $7(14)$ & \\
\hline Ascending & $5(10)$ & $11(22)$ & \\
\hline Transverse & $12(25)$ & $6(12)$ & \\
\hline Desceding & $7(15)$ & $8(16)$ & \\
\hline Sigmoid & $5(10)$ & $3(6)$ & \\
\hline Rectum & $6(13)$ & $15(30)$ & \\
\hline $\begin{array}{l}\text { Tumor site, median } \\
\text { (range, min) }\end{array}$ & $22(51-85)$ & $23(45-87)$ & $0.61^{\mathrm{a}}$ \\
\hline Growth type, n (\%) & & & $0.76^{b}$ \\
\hline LST-G & $22(46)$ & $18(36)$ & \\
\hline LST-NG & $23(48)$ & $28(56)$ & \\
\hline Others & $3(6)$ & $4(8)$ & \\
\hline Histrogy, n (\%) & & & $0.36^{\mathrm{b}}$ \\
\hline Adenoma & $22(46)$ & $18(36)$ & \\
\hline Carcinoma & $23(48)$ & $28(56)$ & \\
\hline Cancer Depth, n (\%) & & & $0.94^{b}$ \\
\hline $\mathrm{m}$ & $12(67)$ & $15(68)$ & \\
\hline sm1 & $3(17)$ & $4(18)$ & \\
\hline $\mathrm{sm} 2$ & $3(17)$ & $3(14)$ & \\
\hline
\end{tabular}

LST: Lateral spreading tumor; G: granular type; NG: non-granular type; sm1: submucosa $1(\mathrm{sm}<1.0 \mathrm{~mm}) ; \mathrm{sm} 2$ : submucosa $2(\mathrm{sm} \geq 1.0 \mathrm{~mm})$. aMann-Whitney $U$-test; bFisher's exact test.

as curative resection with negative margins, and the absence of lymph nodes and vascular invasion (confirmed by histological assessment of the resected specimen). Perforation was defined as the absence of muscle layer during ESD. Muscle injury was also recorded but was not regarded as a complication.

Setting of colorectal ESD. All patients were treated under sedation with pentazocine and midazolam or awareness, depending on the patient's preference or at the operator's discretion. ESD was carried out using a single-channel video endoscope (PCF-Q260AZI or GIFQ260J or GIF-H260Z; Olympus, Tokyo, Japan), with $\mathrm{CO}_{2}$ insufflation during the procedure. A transparent cap (ST hood DH28GR.29CR, Fujifilm Medical, Tokyo, Japan) was attached to the tip of the scope. The electrosurgical unit was a VIO 300D (ERBE, Elektromedizin, Tübingen, Germany), and a DualKnife (1.5 mm, KD-650L/Q; Olympus, Tokyo, Japan) was used for all ESD procedures. If using a DualKnife alone was considered unsafe, an additional device (IT knife-nano; Olympus; or Clutch Cutter; Fujifilm, Tokyo, Japan) was allowed. A Coagrasper (FD-410LR; Olympus) was used to control bleeding. The electrical power setting for the DualKnife was as follows: forced-coagulation mode effect 4, $40 \mathrm{~W}$, for mucosal marking; endo-cut 1 mode effect 2, duration 3 , interval 3 , for mucosal incision; and swift-coagulation mode effect 2, $50 \mathrm{~W}$, for submucosal dissection. The setting for the Coagrasper was soft-coagulation mode effect $4,50 \mathrm{~W}$.

Conventional endoscopic submucosal dissection technique. Marking dots were placed circumferentially approximately $5 \mathrm{~mm}$ outside the 


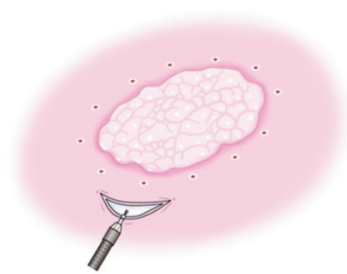

$10 \mathrm{~mm}$ entry at proximal site
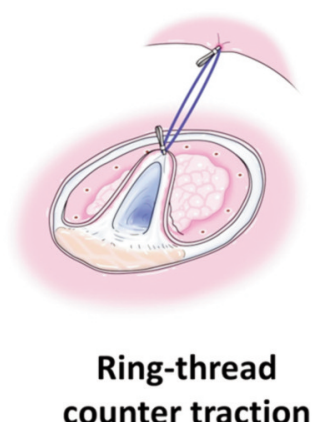

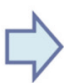

.

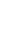
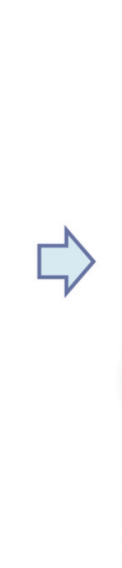

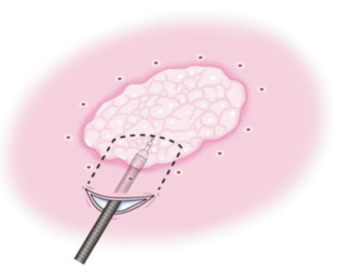

Submucosal pocket creation

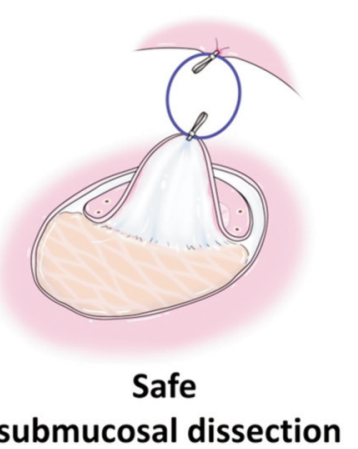

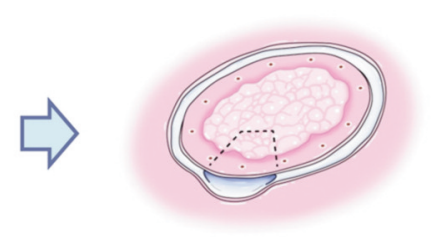

\section{Whole circumferential cutting}

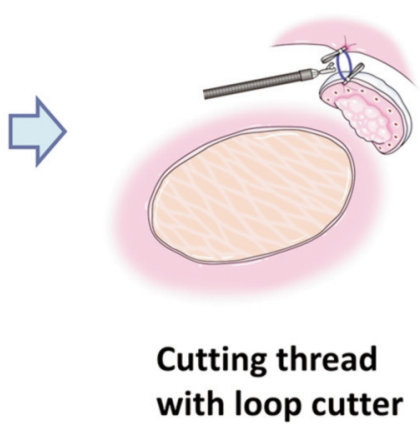

Figure 2. The schema of the pocket creation and ring-thread traction (PRM) procedure.

lesion using a DualKnife. A 1:1 solution of $0.4 \%$ hyaluronate sodium (MucoUp; Johnson and Johnson K.K., Tokyo, Japan) and glycerol (Chugai Pharmaceutical Co. Ltd, Tokyo, Japan), mixed with diluted epinephrine $(1: 200,000)$ and indigo carmine, was injected into the submucosal layer using a 25-G needle (Boston Scientific, Tokyo, Japan). Mucosal incision and submucosal dissection were initially performed from the anal side of the lesion, and the mucosa was incised circumferentially around the lesion. The residual submucosal layer was then dissected completely from the anal side to the oral side. Vessels on the post-ESD defect were coagulated carefully. Finally, the artificial defect was closed with several hemoclips.

PRM. The PRM procedure is summarized in Figure 2. Following local injection approximately $1 \mathrm{~cm}$ proximal to the tumour, a $1-\mathrm{cm}$ lateral mucosal incision was made using a DualKnife to create a submucosal pocket (Figure 3A) of up to one third of the lesion from the proximal to the distal side (Figure 3B). A circumferential incision was then made around the whole lesion (Figure 3C). For traction, we prepared a 2-cm-diameter ring-thread (3-0 surgical nylon) connected to a side hole on the hemoclip (ZEOCLIP ZP-CH; ZEMEX, Tokyo, Japan), and inserted the hemoclip with the ringthread towards the target lesion through the scope channel. The hemoclip was then anchored onto the mucosal flap of the submucosal pocket and fixed on the contralateral mucosa with another hemoclip (EZ Clip HX-202LR; Olympus) while aspirating intraluminal air (Figure 3D). It was possible to adjust the strength of traction with the ring-thread in proportion to the amount of $\mathrm{CO}_{2}$ insufflation. If necessary, the axis of traction could be changed by anchoring another clip on a suitable site and adding another ringthread in the same manner. After submucosal injection, the traction enabled the submucosa to be dissected safely and easily under direct
Table II. Study outcomes.

\begin{tabular}{|c|c|c|c|}
\hline Parameters & $\begin{array}{l}\text { PRM group } \\
\quad(\mathrm{n}=48)\end{array}$ & $\begin{array}{l}\text { Conventional } \\
\text { group }(\mathrm{n}=50)\end{array}$ & $p$-Value \\
\hline $\begin{array}{l}\text { Total procedure times, } \\
\text { Mean } \pm \text { SD }\end{array}$ & $58.9 \pm 25.7$ & $75.9 \pm 35.3$ & $0.007^{\mathrm{a}}$ \\
\hline En-block resection, n (\%) & $48(100)$ & $50(100)$ & $1^{\mathrm{a}}$ \\
\hline Curative resection, n (\%) & $46(96)$ & $46(92)$ & $1^{\mathrm{a}}$ \\
\hline $\begin{array}{l}\text { Resection size (mm), } \\
\text { Mean (range) }\end{array}$ & $34(19-55)$ & $32(19-55)$ & $0.57^{\mathrm{a}}$ \\
\hline Perforation rate, $\mathrm{n}(\%)$ & $1(2)$ & $5(10)$ & $0.205^{\mathrm{b}}$ \\
\hline Muscle burning rate, $\mathrm{n}(\%)$ & $0(0)$ & $4(8)$ & $0.118^{\mathrm{b}}$ \\
\hline $\begin{array}{l}\text { Using aditional device } \\
\text { rate, } \mathrm{n}(\%)\end{array}$ & $4(8)$ & $20(40)$ & $0.00015^{\mathrm{b}}$ \\
\hline
\end{tabular}

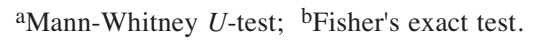

vision from the proximal to the distal side of the tumour (Figure $3 \mathrm{E})$. Finally, the ring-thread was cut with a loop cutter (FS-5L-1; Olympus) after completion of ESD.

Statistical analysis. Continuous variables were presented as mean \pm standard deviation. Differences in categorical variables between two groups were examined by Fisher's exact test when required and continuous variables were compared using Welch's $t$ test. $p<0.05$ was considered statistically significant. All statistical analyses were conducted using JMP 11.2.0 (SAS Institute Inc., Cary, NC, USA). 

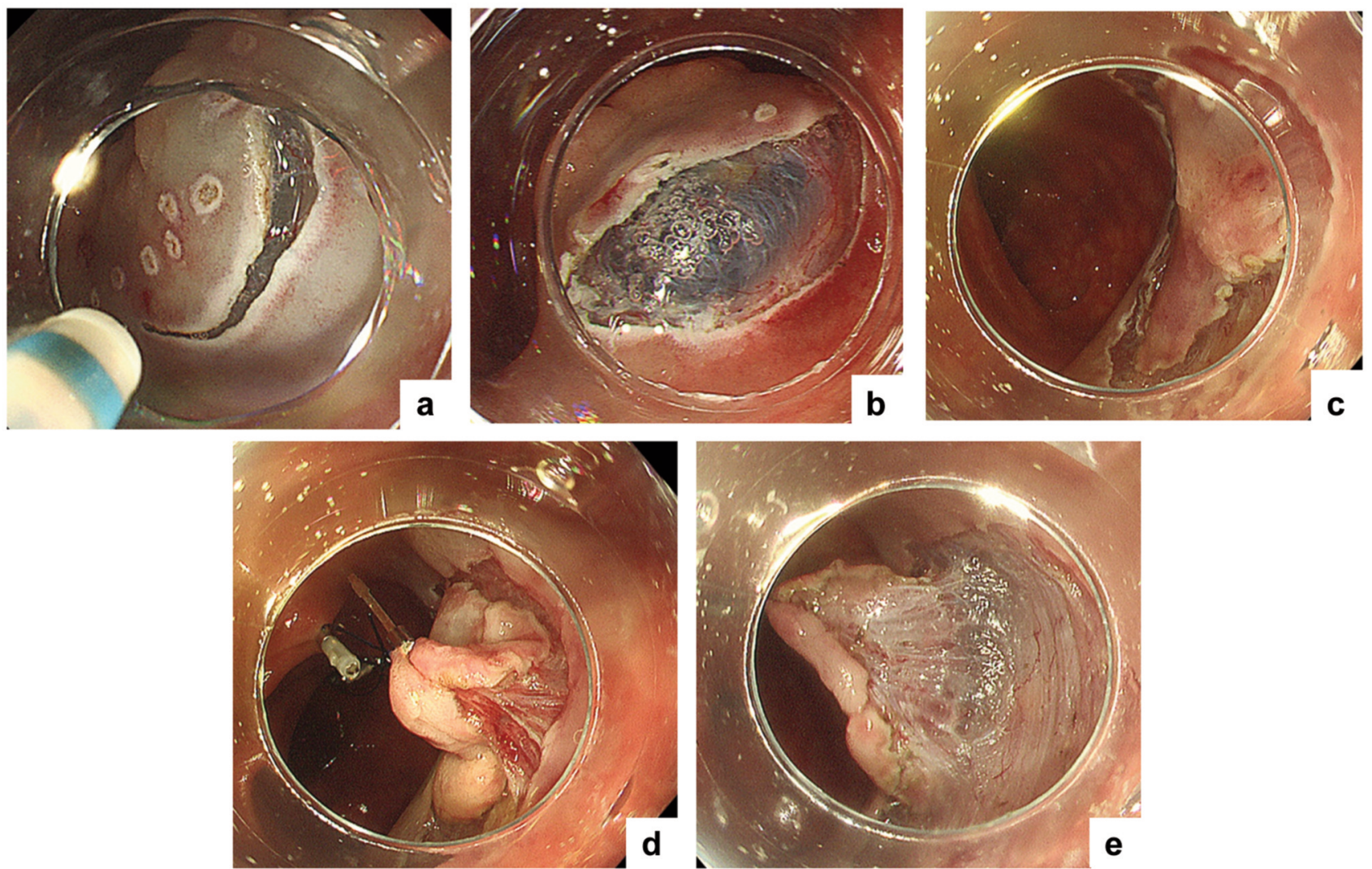

Figure 3. The pictures of the pocket creation and ring-thread traction (PRM) procedure. A) A 1-cm lateral mucosal incision was made using a DualKnife at approximately $1 \mathrm{~cm}$ proximal to the tumour. B) A submucosal pocket was created in up to one third of the lesion from the proximal to the distal side. C) A circumferential incision was then made around the whole lesion. D) The hemoclip was then anchored onto the mucosal flap of the submucosal pocket and fixed on the contralateral mucosa with another hemoclip while aspirating intraluminal air. E) The traction enabled the submucosa to be dissected safely and easily under direct vision from the proximal to the distal side of the tumour.

\section{Results}

The baseline characteristics of the two groups are shown in Table I. There were no significant differences between the two groups. The outcomes of the two groups are summarized in Table II. Patients in the PRM-group had significantly shorter total procedure times compared with the C-group (75.9 vs. $58.9 \mathrm{~min}$, respectively; $p=0.007$ ). Additionally, the PRM-group required significantly fewer additional devices ( $8 \%$ vs. $40 \%, p<0.001)$. However, there were no significant differences in en bloc or curative resection rates between the groups. Patients in the PRM-group tended to have fewer perforation incidents $(2 \% v s .10 \%)$ and fewer muscle injuries (0\% vs. $8 \%$ ) compared with the C-group. One patient in the PRM group had a caecal perforation because of unpredictable severe submucosal fibrosis induced by local injection at a referred hospital. Immediate perforations occurred in five cases in the C-group. The perforation sites were completely closed by hemoclips and all cases were managed conservatively.

\section{Discussion}

The present study indicated that PRM shortened the procedure time and decreased additional device usage compared with conventional ESD in the case of procedures performed by non-experts. PRM may thus be an acceptable strategy for achieving complete colorectal ESD by non-experts.

ESD generally requires advanced skills to dissect the appropriate submucosal layer and promptly manage intraoperative bleeding (15). Among these issues, identifying the dissected plane during ESD is particularly difficult for non-experts $(16,17)$. Previous studies on clip-traction methods have examined the clinical impact of the endoscopist's expertise level (expert vs. non-expert) on colorectal ESD $(9,11)$. Overall, they showed that traction significantly improved the procedure time for both experts and non-experts compared with non-traction groups. These results support the results of the current study.

Several traction methods have been reported to facilitate ESD to date. The clip-flap method increases the accessibility 
of the submucosal layer and makes submucosal tunnelling easier, although the traction force is often inadequate (18). Traction-assist using clip and line (9), ring-thread (10), multiloop (11), and S-O clip (19) are simple and effective methods without reinsertion of the colonoscope; however, these techniques do not include anchoring the hemoclip on the mucosal flap. We introduced PRM to overcome these issues, by combining pocket creation and traction.

PRM has several advantages. 1) Traction maintains better visualization of the submucosal layer and vessels, allowing precise dissection of the correct layer and thus, preventing intraoperative bleeding and perforation. In the current study, the PRM-group tended to show fewer perforation incidents (2\% vs. 10\%, respectively) and fewer muscle injuries (0\% vs. $8 \%$, respectively) compared with the C-group. 2) Creating a submucosal pocket helps to prevent misplacement of the traction clip into the muscle and submucosal layer. 3) PRM provides additional traction force by hooking the ring-thread with another clip towards the more-distal side repeatedly, as well as having the option for additional traction clips and allowing control of the traction force by managing $\mathrm{CO}_{2}$ insufflation. 4) PRM allows ESD to be completed regardless of the lesion location, even by nonexperts, without the need to consider the effects of gravity. 5) Finally, the cost of traction and additional knives is relatively low.

This study had several limitations. First, it was a singlecentre, retrospective study. Second, lesions suspicious for severe submucosal fibrosis were excluded because of the high potential for perforation, and were therefore resected by experts. Third, the two groups were not compared over the same period, because conventional ESD was later replaced by PRM-ESD for all cases. A randomized controlled trial is therefore needed to address these limitations.

In conclusion, the current study indicates that PRM may be a safe, useful, and cost-effective technique for non-experts performing colorectal ESD.

\section{Conflicts of Interest}

The Authors have no conflicts of interest to declare regarding this study.

\section{Authors' Contributions}

A.F, N.N and H.K drafted and wrote the manuscript. K.K, N.T, T.C and N.K were involved in the acquisition of the data. S.F analyzed the data. T.Y, K.O, Y.S, D.N and A.N revised the manuscript. T.M gave final approval of the manuscript.

\section{Acknowledgements}

The Authors thank the medical stuff of Kagawa University Faculty of Medicine, Kanagawa, Japan.

\section{References}

1 Saito Y, Fukuzawa M, Matsuda T, Fukunaga S, Sakamoto T, Uraoka T, Nakajima T, Ikehara H, Fu KI, Itoi T and Fujii T: Clinical outcome of endoscopic submucosal dissection versus endoscopic mucosal resection of large colorectal tumors as determined by curative resection. Surg Endosc 24(2): 343-352, 2010. PMID: 19517168. DOI: 10.1007/s00464-009-0562-8

2 Ono H, Yao K, Fujishiro M, Oda I, Nimura S, Yahagi N, Iishi H, Oka M, Ajioka Y, Ichinose M and Matsui T: Guidelines for endoscopic submucosal dissection and endoscopic mucosal resection for early gastric cancer. Dig Endosc 28(1): 3-15, 2016. PMID: 26234303. DOI: 10.1111/den.12518

3 Tanaka S, Kashida H, Saito Y, Yahagi N, Yamano H, Saito S, Hisabe T, Yao T, Watanabe M, Yoshida M, Kudo SE, Tsuruta O, Sugihara KI, Watanabe T, Saitoh Y, Igarashi M, Toyonaga T, Ajioka Y, Ichinose M, Matsui T, Sugita A, Sugano K, Fujimoto $\mathrm{K}$ and Tajiri H: JGES guidelines for colorectal endoscopic submucosal dissection/endoscopic mucosal resection. Dig Endosc 27(4): 417-434, 2015. PMID: 25652022. DOI: 10.1111/ den. 12456

4 Abe S, Wu SYS, Ego M, Takamaru H, Sekiguchi M, Yamada M, Nonaka S, Sakamoto T, Suzuki H, Yoshinaga S, Matsuda T, Oda I and Saito Y: Efficacy of current traction techniques for endoscopic submucosal dissection. Gut Liver 14(6): 673-684, 2020. PMID: 31887810 . DOI: $10.5009 /$ gnl19266

5 Pimentel-Nunes P, Dinis-Ribeiro M, Ponchon T, Repici A, Vieth M, De Ceglie A, Amato A, Berr F, Bhandari P, Bialek A, Conio M, Haringsma J, Langner C, Meisner S, Messmann H, Morino M, Neuhaus H, Piessevaux H, Rugge M, Saunders BP, Robaszkiewicz M, Seewald S, Kashin S, Dumonceau JM, Hassan C and Deprez PH: Endoscopic submucosal dissection: European Society of Gastrointestinal Endoscopy (ESGE) Guideline. Endoscopy 47(9): 829-854, 2015. PMID: 26317585. DOI: $10.1055 / \mathrm{s}-0034-1392882$

6 Lee BI: Debates on colorectal endoscopic submucosal dissection - traction for effective dissection: gravity is enough. Clin Endosc 46(5): 467-471, 2013. PMID: 24143304. DOI: 10.5946/ ce.2013.46.5.467

7 Sakamoto N, Osada T, Shibuya T, Beppu K, Matsumoto K, Mori H, Kawabe M, Nagahara A, Otaka M, Ogihara T and Watanabe $\mathrm{S}$ : Endoscopic submucosal dissection of large colorectal tumors by using a novel spring-action S-O clip for traction (with video). Gastrointest Endosc 69(7): 1370-1374, 2009. PMID: 19403131. DOI: $10.1016 /$ j.gie.2008.12.245

8 Yamasaki Y, Takeuchi Y, Hanaoka N, Higashino K, Uedo N, Ishihara $\mathrm{R}$ and Iishi $\mathrm{H}$ : A novel traction method using an endoclip attached to a nylon string during colonic endoscopic submucosal dissection. Endoscopy 47 Suppl 1 UCTN: E238-239, 2015. PMID: 26069981. DOI: 10.1055/s-0034-1391868

9 Yamasaki Y, Takeuchi Y, Uedo N, Kanesaka T, Kato M, Hamada K, Tonai Y, Matsuura N, Akasaka T, Hanaoka N, Higashino K, Ishihara R, Okada $\mathrm{H}$ and Iishi $\mathrm{H}$ : Efficacy of traction-assisted colorectal endoscopic submucosal dissection using a clip-andthread technique: A prospective randomized study. Dig Endosc 30(4): 467-476, 2018. PMID: 29424030. DOI: 10.1111/ den.13036

10 Mori H, Kobara H, Nishiyama N, Fujihara S, Matsunaga T and Masaki T: Novel effective and repeatedly available ring-thread counter traction for safer colorectal endoscopic submucosal 
dissection. Surg Endosc 31(7): 3040-3047, 2017. PMID: 27858210. DOI: $10.1007 / \mathrm{s} 00464-016-5326-7$

11 Suzuki Y, Tanuma T, Nojima M, Sudo G, Akahonai M, Hamamoto H, Aoki H, Harada T, Katanuma A and Nakase H: Multiloop as a novel traction method in accelerating colorectal endoscopic submucosal dissection. Gastrointest Endosc 91(1): 185-190, 2020. PMID: 31521780. DOI: 10.1016/j.gie. 2019.08.042

12 Hayashi Y, Miura Y and Yamamoto H: Pocket-creation method for the safe, reliable, and efficient endoscopic submucosal dissection of colorectal lateral spreading tumors. Dig Endosc 27(4): 534-535, 2015. PMID: 25708068. DOI: 10.1111/ den. 12465

13 Hayashi Y, Sunada K, Takahashi H, Shinhata H, Lefor AT, Tanaka A and Yamamoto H: Pocket-creation method of endoscopic submucosal dissection to achieve en bloc resection of giant colorectal subpedunculated neoplastic lesions. Endoscopy 46 Suppl 1 UCTN: E421-422, 2014. PMID: 25314173. DOI: $10.1055 / \mathrm{s}-0034-1377438$

14 Watanabe T, Muro K, Ajioka Y, Hashiguchi Y, Ito Y, Saito Y, Hamaguchi T, Ishida H, Ishiguro M, Ishihara S, Kanemitsu Y, Kawano H, Kingasa Y, Kokudo N, Murofushi K, Nakajima T, Oka S, Sakai Y, Tsuji A, Uehara K, Ueno H, Yamazaki K, Yoshida M, Yoshino T, Boku N, Fujimori T, Itabashi M, Koinuma N, Morita T, Nishimura G, Sakata Y, Shimada Y, Takahashi K, Tanaka S, Tsuruta O, Yamaguchi T, Yamaguchi N, Tanaka T, Kotake K, Sugihara K and Japanese Society for Cancer of the Colon and Rectum: Japanese Society for Cancer of the Colon and Rectum (JSCCR) guidelines 2016 for the treatment of colorectal cancer. Int J Clin Oncol 23(1): 1-34, 2018. PMID: 28349281. DOI: 10.1007/s10147-017-1101-6

15 Saito Y, Otake Y, Sakamoto T, Nakajima T, Yamada M, Haruyama S, So E, Abe S and Matsuda T: Indications for and technical aspects of colorectal endoscopic submucosal dissection. Gut Liver 7(3): 263-269, 2013. PMID: 23710305. DOI: $10.5009 / \mathrm{gnl} .2013 .7 .3 .263$
16 Yoshida M, Takizawa K, Ono H, Igarashi K, Sugimoto S, Kawata N, Tanaka M, Kakushima N, Ito S, Imai K, Hotta K and Matsubayashi H: Efficacy of endoscopic submucosal dissection with dental floss clip traction for gastric epithelial neoplasia: a pilot study (with video). Surg Endosc 30(7): 3100-3106, 2016. PMID: 26487208. DOI: 10.1007/s00464-015-4580-4

17 Suzuki S, Gotoda T, Kobayashi Y, Kono S, Iwatsuka K, YagiKuwata N, Kusano C, Fukuzawa M and Moriyasu F: Usefulness of a traction method using dental floss and a hemoclip for gastric endoscopic submucosal dissection: a propensity score matching analysis (with videos). Gastrointest Endosc 83(2): 337-346, 2016. PMID: 26320698. DOI: 10.1016/j.gie.2015.07.014

18 Yamamoto K, Hayashi S, Saiki H, Indo N, Nakabori T, Yamamoto M, Shibuya M, Nishida T, Ichiba M and Inada M: Endoscopic submucosal dissection for large superficial colorectal tumors using the "clip-flap method". Endoscopy 47(3): 262-265, 2015. PMID: 25412089. DOI: 10.1055/s-00341390739

19 Okamoto Y, Oka S, Tanaka S, Inagaki K, Tanaka H, Matsumoto K, Boda K, Yamashita K, Sumimoto K, Ninomiya Y and Chayama K: Clinical usefulness of the S-O clip during colorectal endoscopic submucosal dissection in difficult-to-access submucosal layer. Endosc Int Open 8(3): E437-E444, 2020. PMID: 32140559. DOI: 10.1055/a-1093-0681
Received January 26, 2021

Revised February 8, 2021

Accepted February 9, 2021 